\title{
CARACTERIZAÇÃO DO RESÍDUO DE CASTANHA COMO SUBSTRATO NA PRODUÇÃO DE PROTEASE POR FUNGO FILAMENTOSO DA AMAZÔNIA
}

\section{CHARACTERIZATION OF CASTANHA RESIDUE AS A SUBSTRATE IN THE PROTEASE PRODUCTION BY FILAMENTAL FUNGUS OF THE AMAZON}

\author{
L. C. NASCIMENTO' ${ }^{1}$, L. A. de O. da $\operatorname{SILVA}^{2}$ e F. N. CESARINO ${ }^{3}$ \\ ${ }^{1}$ Universidade Luterana do Brasil - CEULM/ULBRA, Departamento de Engenharia Química \\ ${ }^{2}$ Universidade Federal de Pernambuco, Departamento de Antibióticos \\ ${ }^{3}$ Universidade Luterana do Brasil - CEULM/ULBRA, Departamento de Engenharia Química \\ E-mail: cardosolillian@hotmail.com
}

\author{
$\frac{\text { article info }}{\text { Article history: }}$ \\ Received 20 May 2016 \\ Accepted 3 January 2017 \\ Available online 27 July 2017
}

\author{
PALAVRAS-CHAVE:Castanha; Resíduo orgânico; Protease. \\ KEYWORDS: Chestnut; Organic waste; Protease.
}

RESUMO: Os processos produtivos da indústria de alimentos podem gerar uma considerável quantidade de resíduos orgânicos, cujo descarte causa impactos de média e de grandes proporções ao meio ambiente. Uma alternativa proposta para a redução de impactos é a utilização dos resíduos orgânicos e de seus subprodutos para a produção de enzimas microbianas como, por exemplo, a protease, sendo esta enzima posteriormente utilizada em outros processos industriais como a fabricação de tecidos, tintas, ou outros gêneros alimentícios. Este trabalho acadêmico apresenta uma avaliação do resíduo da Castanha da Amazônia (Bertholletia excelsa) como substrato em fermentações semi-sólidas, para a produção da protease, com a utilização de microrganismos isolados da microbiota amazônica. Os resultados obtidos mostraram que o resíduo de castanha proporcionou maior sintese de protease alcançando 0,157U/mg de proteina em 120 horas.

\begin{abstract}
The production processes of the food industry can generate a considerable amount of organic waste, whose disposal causes medium and large impacts to the environment. A proposed alternative for the reduction of impacts is the use of organic residues and their by-products for the production of microbial enzymes, such as protease, and this enzyme is subsequently used in other industrial processes such as fabrics, paints, or Other foodstuffs. This academic work presents an evaluation of the residue of the Brazilian Chestnut (Bertholletia excelsa) as substrate in semi-solid fermentations, for the production of protease, using microorganisms isolated from the Amazonian microbiota. The results showed that the brown residue provided a higher protease synthesis reaching $0.157 \mathrm{U} / \mathrm{mg}$ protein in 120 hours.
\end{abstract}

\section{INTRODUÇÃO}

A indústria alimentícia representa uma grande parcela de representatividade na atividade econômica do setor primário. Por conta da magnitude do setor, intrinsicamente os resíduos industriais - em especial os resíduos orgânicos - também são gerados em grandes quantidades ao final dos processos de beneficiamento dos alimentos. Na última década, no 
entanto, tem sido verificado um aumento na quantidade de propostas de solução para o gerenciamento e reaproveitamentos dos resíduos agroindustriais, de modo a agregar valor econômico a este resíduo e minimizar os impactos ambientais gerados pelo mesmo.

O estado do Amazonas é o maior produtor de Castanha da Amazônia (Bertholletia excelsa), com a geração de um resíduo rico em nutrientes orgânicos, o que a torna um substrato com grande potencial para produção de enzimas como as proteases. Tratam-se de enzimas que catalisam a clivagem das ligações peptídicas de proteínas e que apresentam grande importância do ponto de vista industrial, utilizadas em diversas atividades como o processamento de alimentos e bebidas, a formulação de detergentes, o processamento de couro e pele, o amaciamento de carnes, a formulação de medicamentos, a fixação de tintas na indústria têxtil, dentre outras aplicações. A utilização da enzima protease corresponde a cerca de $60 \%$ da utilização do total de enzimas e biocatalisadores. Proteases microbianas, principalmente fúngicas, apresentam vantagens como fácil obtenção e recuperação (KUMAR et al., 2005), o que justifica sua preferência de utilização.

Diversos subprodutos agroindustriais têm sido usados como substratos para a produção de enzimas, devido à disponibilidade local e por representar uma fonte alternativa de baixo valor comercial (MARTINS et al., 2002; MARTINS et al., 2007; SILVA et al.; 2005). As castanhas (amêndoas), em especial, possuem um alto valor energético e são ricas em proteínas, com altos valores nutricionais (SOUZA E MENEZES, 2004).

Face ao exposto, este trabalho tem por objetivo avaliar o resíduo da indústria de beneficiamento da Castanha da Amazônia (Bertholletia excelsa), como substrato em fermentações semi-sólidas para a produção de proteases, por meio da utilização de microrganismos isolados da microbiota amazônica.

\section{MATERIAL E MÉTODOS}

\subsection{Seleção do microrganismo}

O microrganismo utilizado nesse estudo foi um conjunto de fungos filamentosos (Aspergillus sp.) isolados da microbiota amazônica.

\subsection{Preparação do substrato sólido}

O resíduo de Castanha foi doado por uma empresa do ramo alimentício localizada na cidade de Manaus-AM. Este resíduo foi obtido ao final do processo industrial, e utilizado como substrato em fermentação semi-sólida, sem tratamentos adicionais.

\subsection{Preparação do meio para inoculação}

A fermentação foi conduzida por meio da utilização de erlenmeyers de $125 \mathrm{~mL}$ com 2,5g de substrato da Castanha da Amazônia. Foram adicionados $15 \mathrm{~mL}$ da solução de Sulfato de Amônio (NH4)2SO4 (fonte de nitrogênio) dentro do tubo de ensaio com o fungo 
filamentoso (Aspergillus sp.) isolado do solo amazônico, fazendo assim uma solução de esporos. Para contagem dos esporos, foi utilizado o método de Newbauer. Os frascos com resíduo foram esterilizados por 15 minutos no fluxo laminar e logo em seguida inoculou-se a solução fúngica com 108 esporos $/ \mathrm{mL}$ por $2,5 \mathrm{~g}$ de substrato. Os Erlenmeyers foram incubados em temperatura ambiente (média $28^{\circ} \mathrm{C}$ ) durante 120 horas, com amostras sendo retiradas a cada 24 horas.

\subsection{Obtenção dos extratos enzimáticos}

Após cada período de 24 horas de fermentação, foram adicionados $5 \mathrm{~mL}$ de água autoclavada deionizada em cada erlenmeyers, para obtenção dos extratos enzimáticos produzidos pelo fungo. Logo em seguida aplicou-se ultra-som ao fungo durante 2 minutos, procedeu-se a homogeneização da amostra e posteriormente realizada a filtração a vácuo da mesma, com a utilização de papel filtro. O extrato foi utilizado para determinação da atividade enzimática. O experimento foi feito em forma de duplicata onde os resultados são expressos como média encontrada a cada dia.

\subsection{Atividade enzimática da protease}

A atividade proteolítica foi determinada segundo a metodologia de Charney e Tomarelli (1947), com a utilização de azo-caseína como substrato, e ácido tricloroacético como agente de precipitação.

A atividade proteolítica foi determinada por meio da utilização de $30 \mu \mathrm{L}$ de solução enzimática de Castanha da Amazônia, e adição de $50 \mu \mathrm{L}$ de $1 \%$ de azo-caseína (substrato). As amostras reagiram por 1 hora em ambiente ausente de fontes luminosas, com temperatura aproximada de $28^{\circ} \mathrm{C}$. Após este período, foram adicionados $2,4 \mathrm{~mL}$ de ácido tricloroacético a $10 \%$, no intuito de paralisar a reação. Logo em seguida, o material foi centrifugado, a 10.000 rpm por 10 minutos. Do sobrenadante, foram retirados $160 \mu \mathrm{L}$, ao qual adicionou-se $2,4 \mu \mathrm{L}$ de $\mathrm{NaOH}$ 1M. Esta solução foi agitada e levada a leitura no espectrofotômetro com absorbância a 440NM. A unidade de medida expressa foi em unidade de enzima por grama de substrato.

\subsection{Determinação da temperatura ótima de atuação}

Para a determinação de temperatura ótima de atuação dos extratos enzimáticos, foi seguido o processo de determinação da atividade proteolítica utilizado $30 \mu \mathrm{L}$ de solução enzimática de castanha, mais $50 \mu \mathrm{L}$ de $1 \%$ de azo-caseína (substrato). Deixaram-se as amostras reagirem por 1 hora em ausência de iluminação, com temperatura de reação variável entre $35^{\circ} \mathrm{C}$ a $85^{\circ} \mathrm{C}$. Após este período, foram adicionados $2,4 \mathrm{~mL}$ de ácidos tricloroacético a 10\%, para paralisação da reação. Em seguida o material foi centrifugado a $10.000 \mathrm{rpm}$, por 10 minutos. Do sobrenadante, foram retirados $160 \mu \mathrm{L}$, aos quais foram adicionados 2,4 $\mu \mathrm{L}$ de $\mathrm{NaOH}$ 1M. Esta solução foi agitada e levada a leitura no espectrofotômetro, com absorbância a 440NM. 


\subsection{Determinação do pH ótimo de atuação}

Para a determinação de $\mathrm{pH}$ ótimo, foram utilizados $100 \mu \mathrm{L}$ da enzima de castanha com adição de $100 \mu \mathrm{L}$ do Tampão McIlvaine, com pH que varia entre 3,0 e 8,0. Deixaram-se as amostras reagirem por $24 \mathrm{~h}$. Após o tempo de reação foi retirada da amostra $30 \mu \mathrm{L}$ de solução enzimática, adicionada à $50 \mu \mathrm{L}$ de $1 \%$ de azo-caseína (substrato), deixou-se as amostras reagirem por 1 hora no escuro, em temperatura de reação a $45^{\circ} \mathrm{C}$ (temperatura definida como ótima para extrato enzimático). Após este período, foram adicionados $2,4 \mathrm{~mL}$ de ácidos tricloroacético (TCA) a 10\%, para paralisar a reação. Logo em seguida, o material foi centrifugado, a $10.000 \mathrm{rpm}$ por 10 minutos. Do sobrenadante, foram retirados $160 \mu \mathrm{L}$, ao qual adicionou-se $2,4 \mu \mathrm{L}$ de $\mathrm{NaOH} 1 \mathrm{M}$. Esta solução foi agitada e levada a leitura no espectrofotômetro com absorbância a 440NM.

\section{RESULTADOS E DISCUSSÃO}

Um fungo filamentoso (Aspergillus sp.) isolado da microbiota Amazônica para teste de fermentação, com os experimentos sendo feitos em resíduo de castanha. Os experimentos foram feitos em forma de duplicata e os resultados estão expressos como a média de 2 experimentos, observando em qual dia apresentou a melhor atividade proteolítica.

\subsection{Caracterização físico-química do extrato enzimático}

$\mathrm{O}$ extrato enzimatico foi caracterizado com relação ao $\mathrm{pH}$ e temperatura ótimas de atuação, visando encontrar as melhores condições de reação para atividade proteolítica.

\subsection{Atividade proteolítica do extrato enzimático obtido por fermentação em resíduos de castanha como substrato, utilizando solução de sulfato de amônio como fonte de nitrogênio}

Foi analisado o resíduo de castanha como substrato da fermentação, utilizando uma solução de sulfato de amônio $\left(\mathrm{NH}_{4}\right)_{2} \mathrm{SO}_{4}$ a $(0,5 \%)$. Na figura 1 , nota-se que a maior média de atividade proteolítica pelo fungo estudado foi alcançado $0,157 \mathrm{U} / \mathrm{mg}$ de proteína a $120 \mathrm{~h}$.

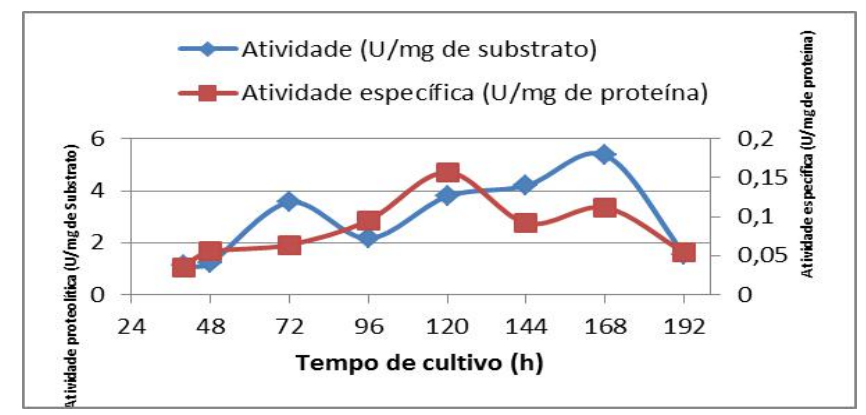

Figura 1: Atividade proteolítica dos extratos enzimaticos obtidos por fermentação semi-sólida, suplementado com sulfato de amonio. - - r- resíduo de castanha. 


\subsection{Determinação da temperatura ótima e pH ótimo do extrato enzimático}

Observou-se, que a melhor temperatura para a atividade proteolitica foi de $45^{\circ} \mathrm{C}$ e $\mathrm{pH}$ ótimo foi de 6,5 .

\section{CONCLUSÃO}

O residuo analisado mostrou-se eficiente como substrato para a produção de protease, com a utilização de um fungo filamentoso isolado da microbiota Amazonica. De acordo com os resultados obtidos, o resíduo de castanha mostrou-se aplicável à síntese de protease, alcançando $0,157 \mathrm{U} / \mathrm{mg}$ de proteína com 120 horas. A caracterização do extrato enzimático revelou o $\mathrm{pH}$ e temperatura ótimos, sendo 6,5 e $45^{\circ} \mathrm{C}$, respectivamente. Esses resultados parciais mostraram que o resíduo de castanha é indutor de protease.

\section{REFERÊNCIAS}

CHARNEY, J. \& TOMARELLI, R.M., (1947), A colorimetric method for the determination of the proteolytic activity of duodenal juice. J. Biol. Chemical., v. 23, p. 501-505.

KUMAR, S.; SHARMA, N. S.; SAHARAM, M. R.; SINGH, R. Extracellular acid protease from Rhizopus oryzae : purification and characterization. Process Biochemistry, 2005.

MARTINS, E. S., Silva, D., LEITE, R. S. R., GOMES, E., da Silva, R. Purification and characterization of polygalacturonase produced by thermophilic Thermoascus aurantiacus 179-5 in submerged fermentation. Antonie van Leeuwenhoek International, v.91, p.291 - 299, 2007.

MARTINS, E. S., Silva, D., da Silva, R., GOMES, E. Solid state production of ther mostable pectinases from thermophilic Thermoascus aurantiacus. Process Biochemistry., v.37, .949-954, 2002.

SILVA, D.; et al. Production of pectinase by solid-state fermentation with Penicillium viridicatum RFC3. Process Biochemistry, v. 40, p. 2885-2889, 2005.

SOUZA, M.L, MENEZES, H.C. Processamentos de Amêndoa e Torta de Castanha-doBrasil e Farinha de Mandioca: parâmetros de qualidade. Ciências e Tecnologia Alimentos, Campinas, 24(1): 120-128, jan.-mar. 2004. 